Article

\title{
Towards Rational Chemosensor Design through Improved Understanding of Experimental Parameter Variation and Tolerance in Cyclodextrin-Promoted Fluorescence Detection
}

\author{
Dana J. DiScenza, Ella Culton, Molly Verderame, Julie Lynch, Nicole Serio and Mindy Levine* \\ Department of Chemistry, University of Rhode Island, Kingston, RI 02881, USA; \\ ddiscenza92@gmail.com (D.J.D.); ellaculton@thegreeneschool.org (E.C.); molly_verderame@my.uri.edu (M.V.); \\ julie_lynch@my.uri.edu (J.L.); ncserio@gmail.com (N.S.) \\ * Correspondence: mindy.levine@gmail.com; Tel.: +1-401-874-4243
}

Received: 18 October 2017; Accepted: 7 December 2017; Published: 12 December 2017

\begin{abstract}
We have previously developed a highly efficient fluorescence-based toxicant-detection method that operates in complex environments to detect aromatic toxicants and toxicant metabolites with high sensitivity and selectivity. This method relies on the ability of $\gamma$-cyclodextrin to act as a supramolecular scaffold, and uses a variety of non-covalent interactions between the cyclodextrin, toxicant, and fluorophore to enable efficient detection. Reported herein is an investigation of the effect of various experimental parameters, including host concentration, temperature, $\mathrm{pH}$, salt, and solvent, on the observed energy-transfer efficiencies. These results advance our understanding of $\gamma$-cyclodextrin-based association complexes and provide crucial information for the development of fluorescence-based sensors using such complexation and the resultant fluorescence-based detection.
\end{abstract}

Keywords: cyclodextrin; energy transfer; optical spectroscopy; linear discriminant analysis; fluorescence detection

\section{Introduction}

Cyclodextrins are supramolecular hosts that are used widely for a variety of applications, including drug delivery [1-3], odor neutralization [4], supramolecular catalysis [5-7], and toxicant detection $[8,9]$. Their hydrophobic interiors allow them to form inclusion complexes with hydrophobic guests $[10,11]$, while their hydrophilic exteriors impart aqueous solubility [12,13]. Previous work by our group has demonstrated the use of cyclodextrin host-guest complexes for toxicant detection applications through the promotion of cyclodextrin-based supramolecular complexes between a small molecule toxicant and a high quantum yield organic fluorophore [14]. In such systems, the close proximity of the toxicant and fluorophore facilitates fluorescence energy transfer, with excitation of the toxicant resulting in energy transfer to and emission from the fluorophore [15]. In cases of non-photophysically active analytes, cyclodextrin promotes interactions between the analyte and the fluorophore, resulting in analyte-specific fluorescence modulation $[16,17]$. We have reported the detection of numerous classes of analytes using these chemosensors, including polycyclic aromatic hydrocarbons (PAHs) [18,19], polychlorinated biphenyls (PCBs) [20], pesticides [21], and aliphatic alcohols [22], as well as the ability of such systems to operate in plasma [23], urine [24], and breast milk [25].

Despite the fact that we have had significant success demonstrating that this cyclodextrin-based system works, a systematic understanding of the parameters under which the system operates is markedly less developed. This understanding requires information about the non-covalent intermolecular forces that underlie such complexation, which are intimately dependent on the molecular 
structures of each component and the experimental conditions. For example, strongly hydrophobic guests that can fit in the hydrophobic cyclodextrin cavity are likely to bind inside; less hydrophobic guests, by contrast, may associate near one of the cyclodextrin rims. Although such rim association has been hypothesized [26], it is difficult to characterize conclusively using experimental methods.

The use of a fluorescence read-out signal for these three-component chemosensor systems is particularly valuable due to the high sensitivity [27] of the fluorescence signal and its strong responsiveness to local environments [28]. Indeed, fluorescence spectroscopy has been used to investigate supramolecular interactions in a number of binary host-guest systems [29-31]. Three-component complexes, including the cyclodextrin-analyte-fluorophore cases investigated herein, are significantly less reported [32-34]. The dependence of the fluorescence read-out signal on the structural features of the small molecule guests, as well as on various experimental conditions has not been systematically investigated to date.

Reported herein are the results of our detailed investigations on the effects of variations in experimental conditions (i.e., temperature fluctuations, solution $\mathrm{pH}$, salt content, and solvent composition) on the intermolecular, proximity-induced, toxicant-to-fluorophore energy transfer. These results indicate that the fluorescence response signal depends intimately on experimental conditions; for example, even small changes in solution $\mathrm{pH}$ can lead to $100 \%$ differentiation in the fluorescence signals at the different $\mathrm{pH}$ values. Nonetheless, the non-covalent energy transfer and presumed intermolecular interactions are sufficiently robust so as to work under a broad range of experimental conditions, including solution $\mathrm{pHs}$ that range from $\mathrm{pH} 0$ to $\mathrm{pH} 12$ and temperatures ranging from $5{ }^{\circ} \mathrm{C}$ to $80^{\circ} \mathrm{C}$. This information is particularly relevant for the rational development of next-generation cyclodextrin-based fluorescent chemosensors.

\section{Materials and Methods}

${ }^{1} \mathrm{H}$ NMR spectra were obtained using a Bruker $300 \mathrm{MHz}$ spectrometer. Fluorescence measurements were recorded on a Shimadzu RF-5301PC spectrophotofluorimeter with $1.5 \mathrm{~nm}$ excitation and $1.5 \mathrm{~nm}$ emission slit widths. For the temperature-dependent studies, a Fisher Scientific Isotemp 6200 R20 was used to control temperature and the spectrophotometer was equipped with a single constant-temperature cell holder. All analytes (compounds 1-6, Figure 1) and $\gamma$-cyclodextrin were purchased from the Sigma-Aldrich Chemical Company and used as received. Fluorophore $\mathbf{7}$ was synthesized following literature-reported procedures [35]. Fluorophores 8 and $\mathbf{9}$ were purchased from Sigma Aldrich and used as received. Arrays were generated using SYSTAT13 statistical analysis software. Computational experiments were performed using Spartan 10 software, with energy-minimized geometries of all analytes and fluorophores.

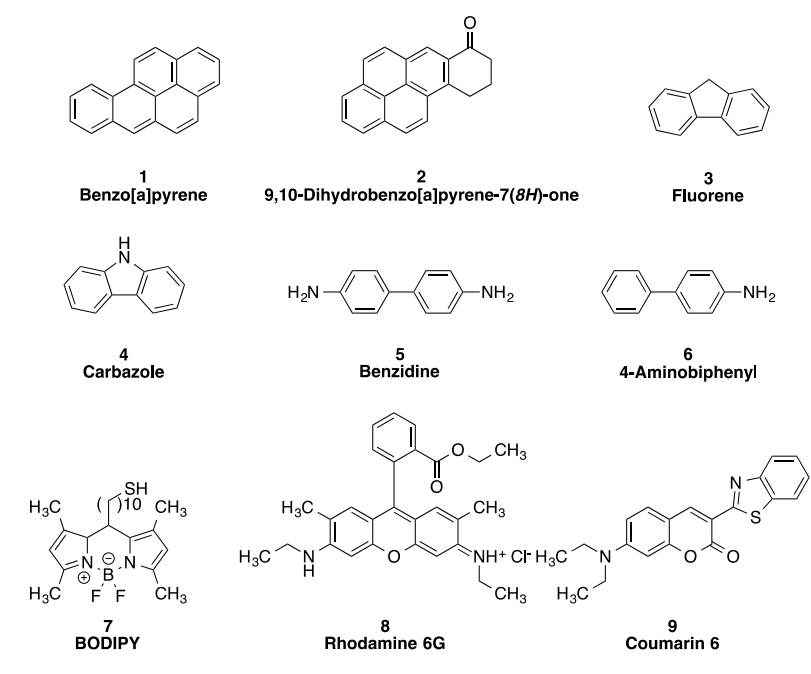

Figure 1. Structures of analytes 1-6 and fluorophores 7-9. 


\subsection{Analyte Selection}

Analytes selected include highly toxic polycyclic aromatic hydrocarbons (1-3), Analyte 4 was chosen as a structurally similar derivative of analyte 3 . Analyte 5 is a toxic and carcinogenic compound commonly used in the textile industry. Analyte $\mathbf{6}$ was chosen as a structurally similar derivative of analyte 5. Overall, this varied analyte selection ensures that the resultant chemosensors are able to detect a variety of structural features, chemical variations, and analyte characteristics, highlighting the broad applicability of the reported results.

\subsection{Cyclodextrin Selection}

Previous work in our group has focused on the use of commercially available cyclodextrins, such as $\alpha$-cyclodextrin, $\beta$-cyclodextrin, methyl- $\beta$-cyclodextrin, 2 -hydroxypropyl- $\beta$-cyclodextrin, and $\gamma$-cyclodextrin, as supramolecular scaffolds to promote energy transfer and fluorescence modulation. For the research reported herein, $\gamma$-cyclodextrin was chosen as the supramolecular host due to its large cavity size and ability to form ternary complexes.

\subsection{General Procedure for Energy Transfer Experiments}

In a quartz cuvette, $2.5 \mathrm{~mL}$ of a $10 \mathrm{mM}$ cyclodextrin solution prepared in phosphate-buffered saline (PBS) was combined with $20 \mu \mathrm{L}$ of analytes $1-6(1.0 \mathrm{mg} / \mathrm{mL}$ in THF). The solution was excited at the analyte and fluorophore's excitation wavelength (see electronic Supplementary Materials (ESI) for more details). Then, $100 \mu \mathrm{L}$ of fluorophores 7-9 were added and the solution was excited at the analyte and fluorophore's wavelength. The fluorescence emission spectra were integrated vs. wavenumber on the $X$-axis, and the efficiency of the energy transfer was quantified as the ratio of the integrated emission of the fluorophore via analyte excitation to the integrated emission of the fluorophore via direct excitation:

$$
\text { Energy transfer efficiency }=I_{\mathrm{DA}} / I_{\mathrm{A}} \times 100 \%
$$

where $I_{\mathrm{DA}}$ is the integration of the fluorophore from analyte excitation and $I_{\mathrm{A}}$ is the integrated fluorophore emission from direct excitation.

Control ratio. Control experiments were conducted as follows: (a) the fluorophore was mixed with $\gamma$-cyclodextrin and excited at the excitation wavelength of the analyte (but in the absence of any analyte); and (b) the fluorophore and analyte were both mixed in $\gamma$-cyclodextrin and excited at the analyte excitation wavelength. The fluorophore emission that resulted from excitation at the analyte wavelength in the absence of the analyte was compared to the fluorophore emission from excitation at the analyte wavelength in the presence of the analyte. The ratio of these two emissions, shown as the "Control ratio," was calculated according to Equation (2):

$$
\text { Control ratio }=I_{\text {fluorophore-control }} / I_{\text {fluorophore-analyte }}
$$

where $I_{\text {fluorophore-analyte }}$ is the integration of the fluorophore emission in the presence of the analyte; and $I_{\text {fluorophore-control }}$ is the integration of the fluorophore emission in the absence of the analyte. For ratios of less than 0.95 , "legitimate" energy transfer was occurring, as indicated by the fact that the presence of the analyte led to higher fluorescence emission (and in turn, a ratio of less than 1.0); for ratios of between 0.95-1.05, the observed fluorescence response was the result of exciting the fluorophore at a wavelength where it has non-zero absorbance, as seen through the fact that the addition of the analyte had virtually no effect on the observed energy transfer efficiency, indicating that the only photophysically active species contributing to the emission was the fluorophore; and for ratios of greater than 1.05, fluorescence quenching was occurring, as indicated by the fact that the presence of the analyte led to a lower fluorescence emission (and in turn, a ratio of above 1.0).

Cyclodextrin solutions. For each experiment, different cyclodextrin solutions were prepared and the energy transfer experiments were modified as follows: 
(a) Concentration effects. Various concentrations of cyclodextrin were used to understand the effect of the host concentration on cyclodextrin-promoted energy transfer. The following concentrations of $\gamma$-cyclodextrin were prepared in phosphate buffered saline (PBS): $5 \mathrm{mM}, 10 \mathrm{mM}$ and $15 \mathrm{mM}$. Energy-transfer experiments were conducted using the above procedures.

(b) Temperature effects. A $10 \mathrm{mM} \gamma$-cyclodextrin solution was prepared in PBS. Energy-transfer experiments were then conducted using the above procedures at the following temperatures: $5{ }^{\circ} \mathrm{C}, 20^{\circ} \mathrm{C}, 35^{\circ} \mathrm{C}, 50^{\circ} \mathrm{C}, 65^{\circ} \mathrm{C}$ and $80^{\circ} \mathrm{C}$. The temperature control system indicated when the desired temperature was reached, and each sample was allowed to sit in the unit after the desired temperature was reached for $5 \mathrm{~min}$ before the fluorescence emission spectrum was collected. Energy-transfer experiments were conducted using the above procedures.

(c) $\mathbf{p H}$ effects. $10 \mathrm{mM} \gamma$-cyclodextrin solutions were prepared using various concentrations of aqueous $\mathrm{HCl}$ and $\mathrm{NaOH}$ at the following $\mathrm{pH}$ levels: 0, 3, 5, 8, 10, 12. Energy-transfer experiments were conducted using the above procedures.

(d) Salt effects. Sodium chloride and guanidinium hydrochloride were used to investigate the effect of chaotropic and kosmotropic salts, respectively, on the cyclodextrin-promoted energy transfer. $1 \mathrm{M}$ solutions of each salt were prepared in deionized water. A $10 \mathrm{mM} \gamma$-cyclodextrin solution was then prepared using these salt solutions. A control experiment was also performed with a $10 \mathrm{mM}$ $\gamma$-cyclodextrin solution in deionized water in the absence of salt. Energy-transfer experiments were then conducted using the above procedures.

(e) Solvent effects. The effect of an ethanol co-solvent on cyclodextrin-promoted energy transfer was investigated. A $10 \mathrm{mM} \gamma$-cyclodextrin solution was prepared in phosphate buffered saline (PBS). For these experiments, $1.25 \mathrm{~mL}$ of $\gamma$-cyclodextrin and $1.25 \mathrm{~mL}$ of ethanol were used $(1: 1 v / v)$. Energy-transfer experiments were then conducted using the above procedures.

\subsection{Array-Generation Procedures}

Array analysis was performed using SYSTAT 13 statistical computing software with the following settings:

(a) Classical discriminant analysis

(b) Grouping variable: analytes

(c) Predictors: $\gamma$-cyclodextrin/BODIPY, $\gamma$-cyclodextrin/Rhodamine 6G, $\gamma$-cyclodextrin/Coumarin 6

(d) Long-range statistics: Mahal

\section{Results and Discussion}

\subsection{Concentration-Dependent Energy-Transfer Experiments}

The effect of the cyclodextrin concentration on the observed fluorescence energy transfer was measured for analytes 1-6 in combination with fluorophore acceptors 7-9. If the formation of ternary complexes between the cyclodextrin, analyte, and fluorophore is required for analyte-to-fluorophore energy transfer, one would expect that the efficiency of the observed energy transfer would increase with an increase in the concentration of the cyclodextrin, as ternary complex formation becomes increasingly favorable. The fact that this phenomenon is not observed in this system for any of the analyte-fluorophore combinations means that: (a) cyclodextrin is not required for the key intermolecular interactions involved in analyte-to-fluorophore energy transfer; (b) the chosen cyclodextrin concentrations are in a region where the energy transfer signal has already reached a maximum value; or (c) more complicated intermolecular phenomena are occurring, including rim association, partial guest inclusion, and/or higher order complexation.

For most combinations of analytes and fluorophores, the change in the cyclodextrin concentration from $5 \mathrm{mM}$ to $10 \mathrm{mM}$ to $15 \mathrm{mM}$ resulted in little to no change in the efficiency of the observed energy transfer, suggesting that the cyclodextrin may be extraneous in promoting favorable intermolecular 
interactions (option a, above), likely as a result of cyclodextrin-free hydrophobic association [19,25]. Some exceptions to this trend include analytes 3 and 4 in combination with fluorophore 7 , for which an increase in the cyclodextrin concentration led to a decrease in the observed energy-transfer efficiencies (Table 1, Figure 2). The decreased efficiencies for these analyte-fluorophore combinations indicate more complicated intermolecular phenomena (option c, above), likely as a result of weaker cyclodextrin-analyte complexation for analytes that are neither extremely hydrophobic (i.e., analytes $\mathbf{1}$ and 2) [36] nor capable of acting as strong hydrogen bond donors (i.e., analytes 5 and 6) [37]. This is further justified through consideration of electrostatic potential maps (see ESI for more details), which were calculated for analytes 1-6 and fluorophores 7-9 in their energy minimized conformations. There is a lower degree of complementarity for analytes $\mathbf{3}$ and $\mathbf{4}$ than with analytes $\mathbf{1}$ and $\mathbf{2}$ (electron-rich) with fluorophores (electron-neutral/electron-deficient surfaces), leading to less interactions and decreased energy-transfer efficiencies.

Table 1. Selected energy-transfer results for concentration-dependent energy-transfer experiments with fluorophore 7 as an acceptor. Control ratios are shown in parentheses ${ }^{a}$.

\begin{tabular}{ccc}
\hline Analyte & Concentration $(\mathbf{m M})$ & Energy Transfer \% (Control Ratio) \\
\hline 1 & 5 & $75.8 \pm 0.06(0.32 \pm 0.02)$ \\
3 & 10 & $44.1 \pm 0.01(0.71 \pm 0.01)$ \\
15 & $40.8 \pm 0.02(0.74 \pm 0.03)$ \\
4 & 1 & $40.5 \pm 0.02(0.79 \pm 0.03)$ \\
\hline & 10 & $134.2 \pm 0.25(0.24 \pm 0.05)$ \\
& 15 & $65.3 \pm 0.00(0.55 \pm 0.03)$ \\
\end{tabular}

a Results represent the average of four trials; energy-transfer efficiencies were calculated using Equation (1); control ratios were calculated using Equation (2).

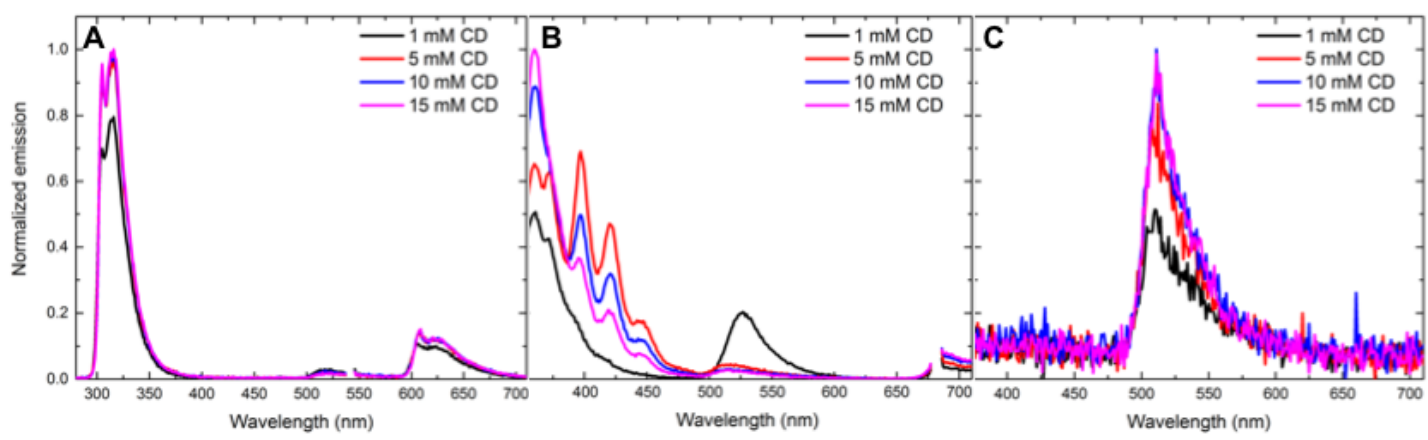

Figure 2. A comparison of the fluorescence emission obtained using $1 \mathrm{mM}$ (black line), $5 \mathrm{mM}$ (red line), $10 \mathrm{mM}$ (blue line) and $15 \mathrm{mM}$ (purple line) $\gamma$-cyclodextrin for (A) analyte 3; (B) analyte 4; and (C) analyte 5 with fluorophore 7.

The observed increases in the control ratios with increasing concentration of cyclodextrin indicate a decreasing effect of the analyte on the observed energy transfer, with the fluorescence emission of the fluorophore changing only slightly in the presence of the analyte $\left(I_{\text {fluorophore-analyte }}\right)$ compared to the emission in the analyte's absence ( $\left.I_{\text {fluorophore-control }}\right)$. This trend was seen for most analyte-fluorophore combinations (see ESI for more details) and can be due to the formation of binary complexes between cyclodextrin and analyte and cyclodextrin and fluorophore, in addition to the ternary cyclodextrin-analyte-fluorophore complexes. Higher cyclodextrin concentrations may also favor the formation of complexes in which more than one cyclodextrin associates with either the analyte and/or the fluorophore, analogous to other literature-reported complexes [38,39]. Such complexes, in turn, effectively limit interactions between the analyte and fluorophore, resulting in a fluorophore 
emission that is relatively unaffected by the presence of the analyte. For the remainder of the studies, we chose $10 \mathrm{mM}$ cyclodextrin solutions based on previously reported results showing high performance of $10 \mathrm{mM}$ cyclodextrin in promoting energy transfer [19-21,23].

\subsection{Temperature-Dependent Energy-Transfer Experiments}

The effect of temperature on the cyclodextrin-promoted energy transfer was measured for analytes 1-6 in combination with fluorophore acceptors 7-9. Because higher temperatures are known to disrupt intermolecular complexation in cyclodextrin-based systems, the performance of the chemosensor under such conditions needed evaluation [40,41]. Results are reported in Table 2, with some key results highlighted in Figure 3. Of note, solutions at $5{ }^{\circ} \mathrm{C}$ are not as near to freezing as a pure water solution might be, because of the high concentrations of electrolytes in the buffer leading to freezing-point depression.

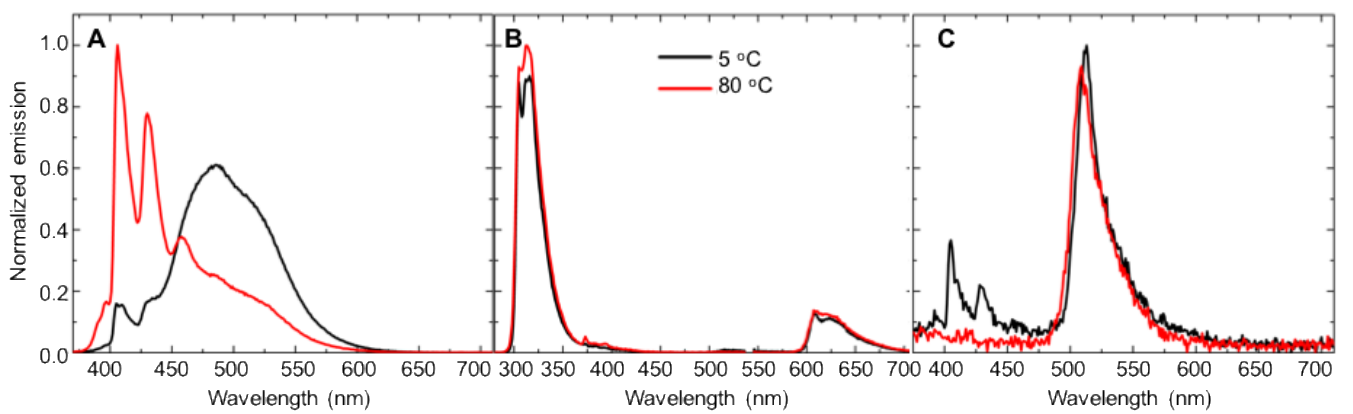

Figure 3. A comparison of the fluorescence emission obtained at $5{ }^{\circ} \mathrm{C}$ (black line) and $80{ }^{\circ} \mathrm{C}$ (red line) for $\gamma$-cyclodextrin with (A) analyte 2; (B) analyte 3; and (C) analyte 5 with fluorophore 7.

Table 2. Selected results of temperature-dependent energy-transfer experiments for analytes 1-6 with fluorophore acceptors 7-9 (control ratios are shown in parentheses) ${ }^{a}$.

\begin{tabular}{ccccc}
\hline Analyte & Temperature $\left({ }^{\circ} \mathbf{C}\right)$ & Fluorophore 7 & Fluorophore 8 & Fluorophore 9 \\
\hline \multirow{2}{*}{$\mathbf{1}$} & 5 & $501.1 \pm 0.21(0.16 \pm 0.01)$ & $36.4 \pm 0.00(0.19 \pm 0.00)$ & $463.4 \pm 0.01(0.02 \pm 0.00)$ \\
\cline { 2 - 4 } & 80 & $290.5 \pm 0.02(0.08 \pm 0.00)$ & $10.5 \pm 0.00(0.34 \pm 0.00)$ & $171.0 \pm 0.01(0.06 \pm 0.00)$ \\
\hline \multirow{2}{*}{$\mathbf{2}$} & 5 & $102.1 \pm 0.00(0.33 \pm 0.00)$ & $15.5 \pm 0.00(0.56 \pm 0.00)$ & $88.5 \pm 0.00(0.22 \pm 0.00)$ \\
\cline { 2 - 5 } & 80 & $62.2 \pm 0.00(0.33 \pm 0.00)$ & $8.3 \pm 0.00(0.97 \pm 0.00)$ & $45.5 \pm 0.00(0.28 \pm 0.00)$ \\
\hline \multirow{2}{*}{$\mathbf{3}$} & 5 & $34.3 \pm 0.01(0.86 \pm 0.02)$ & $13.0 \pm 0.00(0.54 \pm 0.00)$ & $52.9 \pm 0.00(0.61 \pm 0.01)$ \\
\hline \multirow{2}{*}{$\mathbf{4}$} & 80 & $21.4 \pm 0.00(1.03 \pm 0.02)$ & $8.9 \pm 0.07(0.43 \pm 0.00)$ & $21.1 \pm 0.00(0.64 \pm 0.01)$ \\
\hline \multirow{2}{*}{$\mathbf{5}$} & 5 & $87.3 \pm 0.02(0.35 \pm 0.01)$ & $11.8 \pm 0.00(1.05 \pm 0.00)$ & $71.1 \pm 0.01(0.37 \pm 0.00)$ \\
\hline \multirow{2}{*}{$\mathbf{6}$} & 80 & $26.3 \pm 0.00(0.94 \pm 0.01)$ & $10.0 \pm 0.00(1.07 \pm 0.00)$ & $17.5 \pm 0.00(0.93 \pm 0.01)$ \\
\hline & 5 & $33.9 \pm 0.00(1.02 \pm 0.00)$ & $6.2 \pm 0.00(1.09 \pm 0.00)$ & $33.6 \pm 0.01(0.70 \pm 0.03)$ \\
\hline
\end{tabular}

${ }^{\mathrm{a}}$ Results represent the average of four trials; energy-transfer efficiencies were calculated using Equation (1); control ratios were calculated using Equation (2).

As expected, in every case the observed energy-transfer efficiencies were lower at $80^{\circ} \mathrm{C}$ than at $5{ }^{\circ} \mathrm{C}$ (intermediate temperatures reported in the ESI). This is due to a decrease in the strength of intermolecular forces at elevated temperatures, which decreases the stability of the complex and the resultant analyte-to-fluorophore energy transfer. These results are in line with literature reports that indicate that host-guest inclusion complexes [42], including cyclodextrin-based complexes [43], are less stable at higher temperatures. Nonetheless, the measurable fluorescence signals observed 
at $80{ }^{\circ} \mathrm{C}$ indicate that the system still functions to enable proximity-induced fluorescence-based detection even at elevated temperatures. Additionally, for most of the donor-acceptor combinations, control ratios confirm that the observed energy-transfer efficiencies are a result of legitimate analyte-to-fluorophore energy transfer, rather than a result of directly exciting the fluorophore at the analyte's excitation wavelength.

Moreover, Figure 3A indicates a substantial change in the benzo[ $a$ ]pyrene fluorescence emission on going from $5{ }^{\circ} \mathrm{C}$ to $80^{\circ} \mathrm{C}$, with higher excimer emission observed at the lower temperature. This is in line with literature reports that indicate higher excimer amounts at low temperatures [44-46], and is likely due to increased solution viscosity resulting in decreased molecular motion, as well as an increase in the favorability of excimer formation. In contrast, analytes 3 and 5, with no reported excimer formation, show a slight decrease in the fluorescence emission of fluorophore 7 at $80{ }^{\circ} \mathrm{C}$ compared to the emission at $5^{\circ} \mathrm{C}$, but the spectral fine structure is largely maintained. Additional temperatures between $5{ }^{\circ} \mathrm{C}$ and $80{ }^{\circ} \mathrm{C}$ were also tested (see ESI for more details); however, no clear trend existed with slight temperature variations.

The knowledge gained from these temperature-dependent experiments can aid substantially in the rational design of chemosensors, by confirming the ability of the system to operate within a broad temperature range. While the observed energy-transfer efficiencies decrease with increases in the solution temperature, sufficiently favorable intermolecular interactions exist to facilitate analyte-to-fluorophore energy transfer and the resultant turn-on fluorophore emission. Moreover, linear discriminant analysis of the fluorescence response signals shows $100 \%$ differentiation in the fluorescence signals at both low and high temperatures (Figure 4).

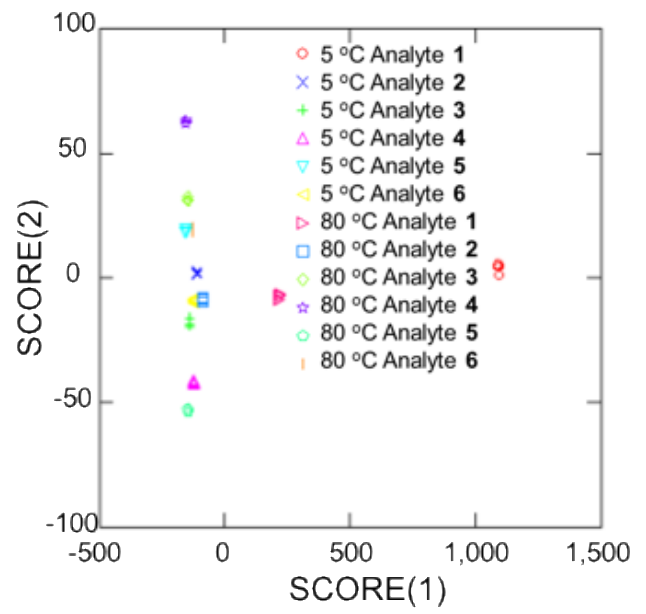

(A)

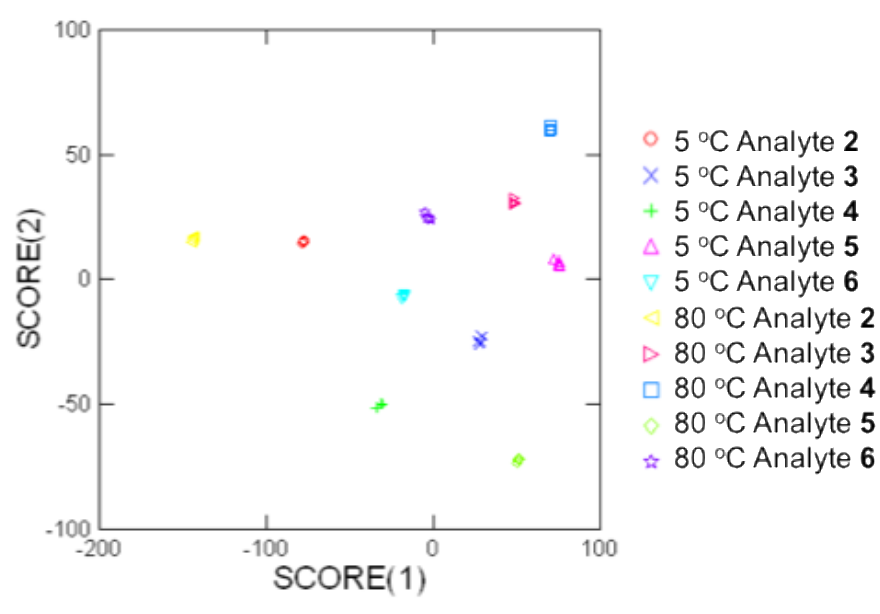

(B)

Figure 4. Array-based detection of (A) analytes 1-6; (B) analytes 2-6 with fluorophores 7-9 in $\gamma$-cyclodextrin solutions at $5^{\circ} \mathrm{C}$ and $80^{\circ} \mathrm{C}$.

Results from statistical arrays generated using analytes 1-6 with fluorophores 7-9 in Figure 4A show an interesting linear grouping of analytes. The observed grouping of analytes is likely due to the large difference in response signals for analyte 1 at both $5^{\circ} \mathrm{C}$ and $80{ }^{\circ} \mathrm{C}$ as compared to analytes $2-6$ at the same temperatures. When the anomalous analyte $\mathbf{1}$ is removed from the statistical array, a greater visual separation of analytes arises (Figure 4B). These results show well-separated response signals for structurally similar analytes (analytes 3 and 4 or analytes $\mathbf{5}$ and $\mathbf{6}$ ) as well as single analytes at different temperatures $\left(5^{\circ} \mathrm{C}\right.$ analyte 2 and $80^{\circ} \mathrm{C}$ analyte 2$)$. These results indicate differences in response signals arising from the different temperature cyclodextrin-analyte-fluorophore combinations, which highlights the practical applicability of these chemosensors to be used for detection in a wide range of temperatures. 


\section{3. $p H$-Dependent Energy-Transfer Experiments}

The $\mathrm{pH}$ of the solution affects the non-covalent interactions between the cyclodextrin, analyte, and fluorophore and the resultant fluorescence energy transfer in a number of ways [47], including: (a) protonation or deprotonation of the analyte, which affects its ability to form intermolecular hydrogen bonds and/or bind in a hydrophobic cavity; (b) protonation or deprotonation of the fluorophore, which will have similar effects; (c) protonation or deprotonation of the cyclodextrin host, which can be ruled out under most circumstances based on the pKa of the hydroxyl groups [48-50]; and (d) modification of the bulk solvent hydrophobicity due to the presence of excess ions, which is a phenomenon that has been well-documented in the literature [51,52]. We investigated the efficiency of the cyclodextrin-promoted energy transfer at $\mathrm{pH} 0,3,5,8,10$ and 12 , and the results of these experiments are summarized in Table 3 and Figure 5.

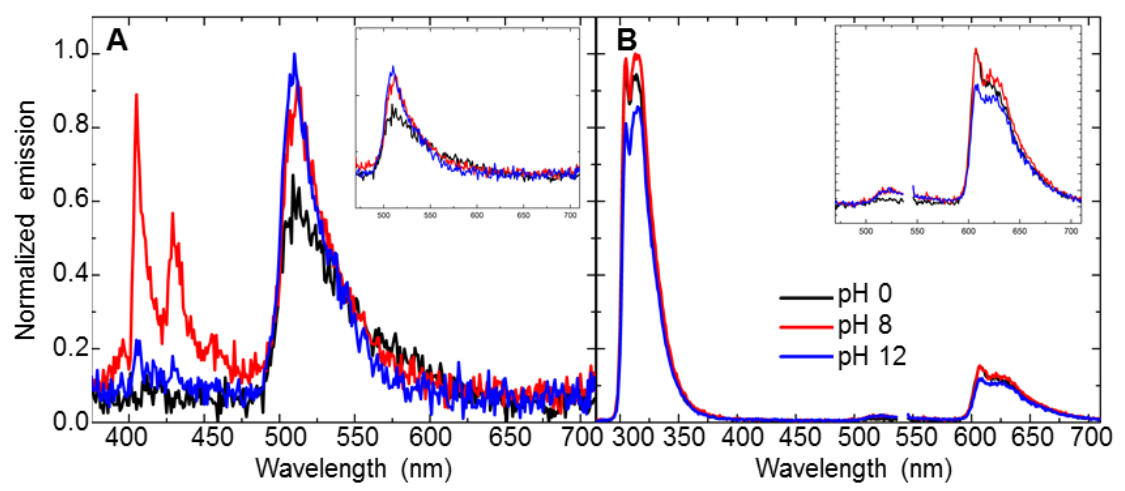

Figure 5. A comparison of the fluorescence emission in $\gamma$-cyclodextrin at $\mathrm{pH} 0$ (black line) and $\mathrm{pH} 8$ (red line), and pH 12 (blue line) with (A) analyte 5; and (B) analyte 6 with fluorophore 7. Insets show the zoomed-in spectral region from $470-800 \mathrm{~nm}$.

Table 3. Select results of energy-transfer experiments with compound 7 (control ratios shown in parentheses) ${ }^{a}$.

\begin{tabular}{ccc}
\hline Analyte & $\mathbf{p H}$ & Energy Transfer \% (Control Ratio) \\
\hline & 0 & $35.4 \pm 0.00(1.09 \pm 0.00)$ \\
3 & $39.7 \pm 0.00(1.19 \pm 0.01)$ \\
5 & 5 & $38.4 \pm 0.00(1.18 \pm 0.00)$ \\
& 8 & $42.4 \pm 0.00(0.26 \pm 0.01)$ \\
& 10 & $40.1 \pm 0.00(1.08 \pm 0.01)$ \\
& 0 & $36.3 \pm 0.01(1.10 \pm 0.03)$ \\
\hline & 3 & $56.1 \pm 0.00(0.70 \pm 0.00)$ \\
& 5 & $60.0 \pm 0.00(0.64 \pm 0.01)$ \\
& 8 & $73.3 \pm 0.01(0.54 \pm 0.00)$ \\
& 10 & $79.4 \pm 0.02(0.13 \pm 0.00)$ \\
& 12 & $71.9 \pm 0.01(0.53 \pm 0.00)$ \\
\end{tabular}

\footnotetext{
a Results represent the average of four trials; energy-transfer efficiencies were calculated using Equation (1); control ratios were calculated using Equation (2).
}

For analytes 5 and $\mathbf{6}$, with one and two free $\mathrm{NH}_{2}$ groups, respectively, the $\mathrm{pH}$-dependent trends in the energy-transfer efficiencies can be explained by the protonation/deprotonation of the analytes (option a, above). Both analytes show maxima in energy-transfer efficiencies at $\mathrm{pHs} 8$ and 10, which correspond to the $\mathrm{pHs}$ at which the $\mathrm{NH}_{2}$ group is neutral (neither protonated nor deprotonated) [53,54]. The neutral $\mathrm{NH}_{2}$ group is better equipped to participate in intermolecular hydrogen bonding and intermolecular hydrophobic association compared to its protonated and 
deprotonated charged analogues, which are the predominant species at lower and higher $\mathrm{pH}$ values, respectively. Moreover, in these cases the residual analyte emission is also significantly stronger at pH 8 compared to pHs 0 and 12 (Figure 5A,B), which indicates that the solution at extreme pH values may be experiencing generally suppressed fluorescence as a result of the high ion content that leads to non-radiative decay pathways.

In general, the fact that strong energy transfer signals are observed within such a broad $\mathrm{pH}$ range highlights the general applicability of this system for working in both extremely acidic and extremely basic solutions. In combination with this general applicability is a high level of selectivity in differentiating all responses at all $\mathrm{pH}$ values with $100 \%$ selectivity (see ESI for more details). The generality and selectivity reported herein have significant applicability in the development of practical chemosensor systems.

\subsection{Salt-Dependent Energy-Transfer Experiments}

Salts are known to influence inclusion complexation by a variety of pathways, including through the disruption of intermolecular hydrogen bonding, the formation of association complexes with hydrophobic and/or charged analytes, and the facilitation of ternary complex formation [55-57]. Their presence also affects hydrophobic association, with salts such as sodium chloride increasing hydrophobic binding [58], and salts such as guanidinium hydrochloride ( $\mathrm{GuHCl})$ decreasing the hydrophobic interactions [59]. Fluorescence energy transfer in these cyclodextrin systems was measured at various salt concentrations (1 M guanidium hydrochloride and $1 \mathrm{M}$ sodium chloride for all analytes and $0.1 \mathrm{M}$ and $2 \mathrm{M}$ concentrations for select analytes) to determine the robustness of the system to operate under conditions known to disrupt important intermolecular interactions. The results are summarized in Table 4, with selected examples shown in Figure 6.

Table 4. Results of energy-transfer experiments in the presence of salt additives with compound 7 (control ratios are shown in parentheses) ${ }^{\mathrm{a}}$.

\begin{tabular}{ccccccc}
\hline Analyte & $\mathbf{0 . 1} \mathbf{~ M ~ N a C l}$ & $\mathbf{1 ~} \mathbf{~ N ~ N a C l}$ & $\mathbf{2 ~ M ~ N a C l}$ & $\mathbf{0 . 1} \mathbf{~ M ~ G u H C l}$ & $\mathbf{1} \mathbf{~ M ~ G u H C l}$ & $\mathbf{2 ~ M ~ G u H C l}$ \\
\hline \multirow{2}{*}{$\mathbf{2}$} & $71.3 \pm 0.00$ & $69.8 \pm 0.03$ & $69.6 \pm 0.01$ & $75.6 \pm 0.00$ & $67.1 \pm 0.01$ & $66.3 \pm 0.01$ \\
& $(0.47 \pm 0.00)$ & $(0.49 \pm 0.00)$ & $(0.55 \pm 0.01)$ & $(0.49 \pm 0.00)$ & $(0.49 \pm 0.01)$ & $(0.51 \pm 0.01)$ \\
\hline \multirow{2}{*}{$\mathbf{4}$} & $40.5 \pm 0.00$ & $51.4 \pm 0.01$ & $84.3 \pm 0.08$ & $40.1 \pm 0.01$ & $41.4 \pm 0.01$ & $50.2 \pm 0.08$ \\
& $(0.92 \pm 0.01)$ & $(0.78 \pm 0.01)$ & $(0.49 \pm 0.04)$ & $(0.900 .01)$ & $(0.89 \pm 0.02)$ & $(0.71 \pm 0.10)$ \\
\hline \multirow{2}{*}{5} & $37.6 \pm 0.01$ & $40.0 \pm 0.00$ & $43.3 \pm 0.01$ & $38.1 \pm 0.00$ & $37.7 \pm 0.00$ & $33.6 \pm 0.00$ \\
& $(1.03 \pm 0.01)$ & $(1.14 \pm 0.00)$ & $(1.01 \pm 0.01)$ & $(1.030 .00)$ & $(1.07 \pm 0.01)$ & $(1.02 \pm 0.00)$ \\
\hline
\end{tabular}

${ }^{a}$ Results represent the average of four trials; energy-transfer efficiencies were calculated using Equation (1); control ratios were calculated using Equation (2).

As expected, a majority of the analyte-fluorophore combinations showed changes in the observed energy transfer efficiencies with changes in the salt composition. In general, sodium chloride solutions demonstrated energy-transfer efficiencies that were slightly higher, indicating an increase in favorable hydrophobic interactions, whereas guanidinium hydrochloride-containing solutions demonstrated energy-transfer efficiencies that were slightly lower. Benzo[a]pyrene $\mathbf{1}$ and the oxidized analogue 2 (Figures 6A and 7A) both demonstrated an increase in the excimer emission in the presence of guanidium hydrochloride compared to the emission in the presence of sodium chloride and the emission in pure distilled water. These compounds have large hydrophobic surfaces that are particularly susceptible to the "salting out effect", in which the addition of certain salts decreases the solubility of the analytes and induces aggregation. This aggregation, in turn, results in a marked increase in the excimer emission (Figures 6 and 7). 


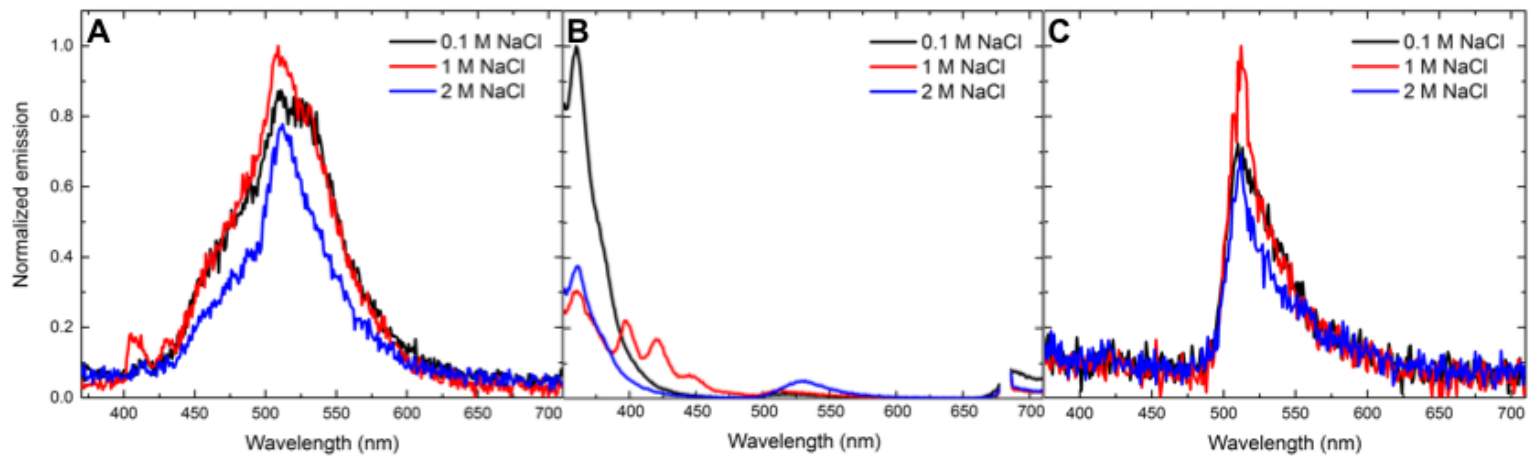

Figure 6. A comparison of the fluorescence emission in $\gamma$-cyclodextrin with $0.1 \mathrm{M} \mathrm{NaCl}$ (black line), $1 \mathrm{M} \mathrm{NaCl}$ (red line), and $2 \mathrm{M} \mathrm{NaCl}$ (blue line) with (A) analyte 2; (B) analyte 4; and (C) analyte 5 with compound 7.

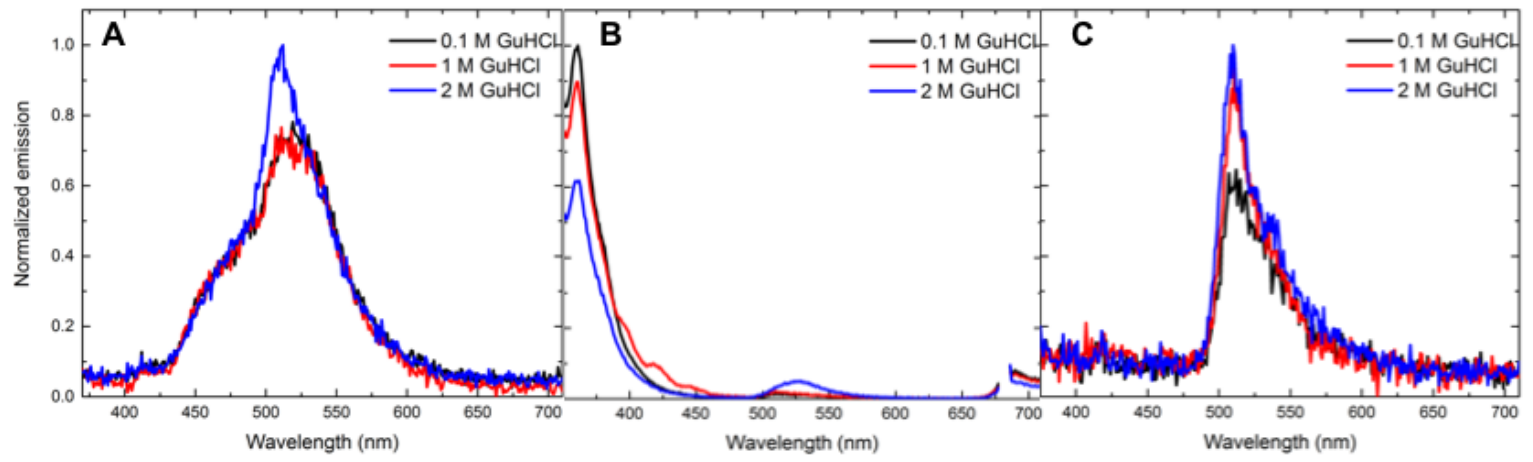

Figure 7. A comparison of the fluorescence emission in $\gamma$-cyclodextrin with $0.1 \mathrm{M} \mathrm{GuHCl}$ (black line), $1 \mathrm{M} \mathrm{GuHCl}$ (red line), and $2 \mathrm{M} \mathrm{GuHCl}$ (blue line) with (A) analyte 2; (B) analyte 4; and (C) analyte 5 with compound 7.

The observed salt dependence in energy transfer efficiencies highlights the tunability of chemosensor performance by adding chaotropic and kosmotropic agents. Based on the structures of each of the components, the addition of salt can either increase or decrease the efficiency of energy transfer, which can be useful in the development of practical chemosensors to be used in different environments of varying salinity.

\subsection{Solvent-Dependent Energy-Transfer Experiments}

The addition of organic co-solvents to aqueous solutions of cyclodextrins can disrupt the interface between the hydrophilic exterior of the cyclodextrin and the bulk aqueous solvent $[60,61]$. In the case of alcohol-based co-solvents, this is due to the hydroxyl moiety of the alcohol forming hydrogen bonds with the hydroxyl groups of cyclodextrin and the hydrophobic portion of the alcohol entering the hydrophobic cyclodextrin cavity [62]. In the case of heterocyclic organic solvents such as THF, this is due to the oxygen heteroatom forming hydrogen bonds with the cyclodextrin while the hydrophobic portion of the molecule entering the cyclodextrin cavity [63]. Furthermore, ternary cyclodextrin-analyte-solvent complexes may form, which can have notable effects on energy-transfer efficiencies [64]. The results of energy-transfer experiments conducted in the absence of organic co-solvent (10 mM $\gamma$-cyclodextrin in PBS), in the presence of ethanol (1:1 volume ratio with $10 \mathrm{mM}$ $\gamma$-cyclodextrin in PBS), and in the presence of THF (1:1 volume ratio with $10 \mathrm{mM} \gamma$-cyclodextrin in PBS) are summarized in Table 5, with control ratios in parentheses, and selected results are shown in Figure 8. 
Table 5. Results of select energy-transfer experiments in the absence and presence of ethanol and THF co-solvents with compound 7 (control ratios are shown in parentheses) ${ }^{a}$.

\begin{tabular}{cccc}
\hline Analyte & GCD & GCD + Ethanol & GCD + THF \\
\hline $\mathbf{1}$ & $1056.7 \pm 0.10(0.03 \pm 0.00)$ & $12.7 \pm 0.00(1.51 \pm 0.01)$ & $15.8 \pm 0.00(1.23 \pm 0.02)$ \\
$\mathbf{3}$ & $40.8 \pm 0.02(0.74 \pm 0.03)$ & $2.5 \pm 0.00(7.70 \pm 0.04)$ & $5.10 \pm 0.00(3.73 \pm 0.07)$ \\
$\mathbf{6}$ & $69.4 \pm 0.00(0.57 \pm 0.01)$ & $5.6 \pm 0.00(3.37 \pm 0.01)$ & $7.84 \pm 0.00(2.63 \pm 0.03)$ \\
\hline
\end{tabular}

${ }^{a}$ Results represent the average of four trials; energy-transfer efficiencies were calculated using Equation (1); control ratios were calculated using Equation (2).

Results in Table 5 indicate that the energy-transfer efficiencies were markedly diminished in ethanol and THF compared to the results in the co-solvents' absence, combined with a marked increase in the calculated control ratios in the organic solvent-containing solutions. These results can be explained by a decrease in the aqueous composition of the solvent, which in turn leads to a decrease in the hydrophobic driving force for cyclodextrin complex formation, which is maximized in a strongly hydrophilic aqueous solvent to favor the inclusion of non-polar aromatic guests. Additionally, the fluorescence intensities were markedly increased in the presence of the co-solvents, likely due to the increased solubility of analytes and fluorophores leading to increased interactions.

Additionally, analyte benzo[a]pyrene $\mathbf{1}$ displayed a strong excimer emission in purely aqueous environments, which overlapped significantly with the fluorescence emission of most fluorophores and complicated accurate quantification of the energy-transfer peak even after spectral deconvolution. In the presence of ethanol or THF co-solvents, this excimer peak is markedly decreased, leading to an easily observable energy-transfer peak (Figure 8A). The decrease in benzo[a]pyrene excimer emission is due to three possible, likely co-existing chemical phenomena: (a) the formation of ternary complexes between the cyclodextrin, benzo[a]pyrene, and organic solvent, analogous to those previously described in the literature and observed in our research $[25,62,63]$; (b) a less hydrophobic environment that makes the co-facial $\pi-\pi$ stacking in the benzo[a]pyrene excimer less favorable; and (c) increased solubility of benzo[a]pyrene in the organic solvent, which prevents any notable analyte-analyte interactions and resultant excimer emission.

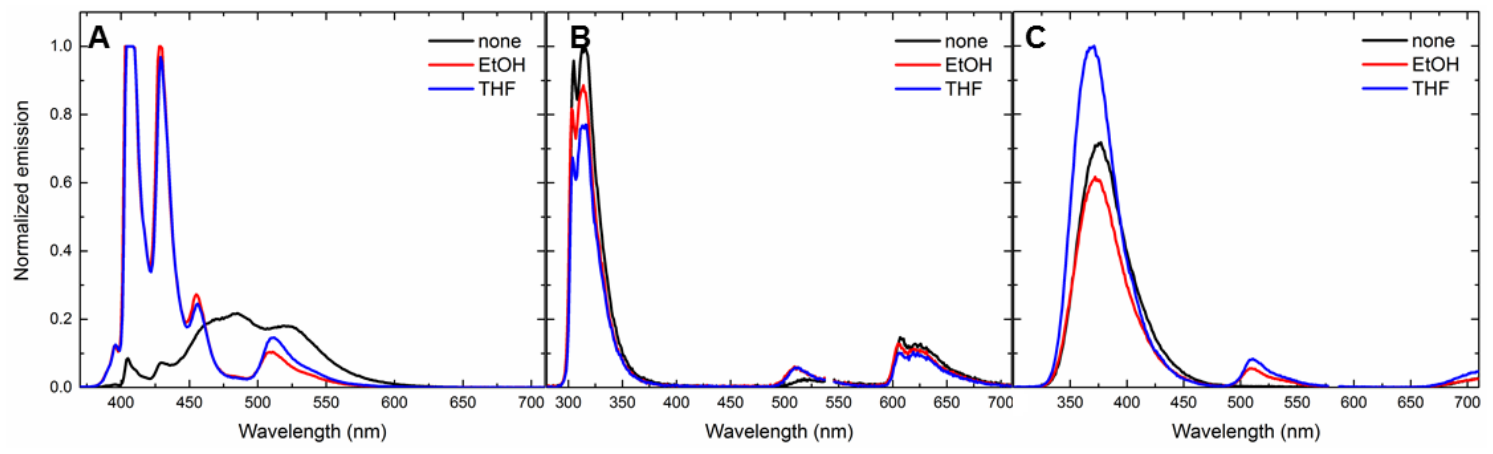

Figure 8. A comparison of the fluorescence emission in $\gamma$-cyclodextrin in the absence (black line) and presence of ethanol (red line) and THF (blue line) with (A) analyte 1; (B) analyte 3; and (C) analyte 6 with compound 7.

The differences seen in energy-transfer quantification and excimer emission in the presence of purely aqueous environments compared to organic solvents highlight the importance of solvent selection in rational chemosensor design. In cases where there is strong excimer emission, a simple change of solvent will drastically improve the performance of the chemosensor. This phenomenon highlights the ability to modify the system in order to develop practically useful read-out signals using straightforward experimental modifications. 


\section{Conclusions}

The ability to modify the performance of chemosensors through the variation of experimental parameters, and the knowledge of what experimental parameter variations are tolerated by the chemosensor system, are both extremely important in the rational design, development, and optimization of chemosensors. Previous work in our group reported the development of cyclodextrin-based chemosensors for toxicant detection applications, but included very little information about the system tolerance to significant experimental fluctuations. Reported herein are the results of our investigations into precisely this objective, in which we show that the cyclodextrin-based chemosensors continue to function even at extremes of temperature, $\mathrm{pH}$, and salt concentrations. These results provide crucial information for the development of fluorescence-based chemosensors using cyclodextrin-based systems to promote fluorescence energy transfer and/or fluorescence modulation. Current research in our laboratory is focused on the use of this knowledge for the development and deployment of practical toxicant-detection systems based on these chemosensors. Results of these and other investigations will be reported in due course.

Supplementary Materials: The following are available online at www.mdpi.com/2227-9040/5/4/34/s1, Supplementary information contains synthesis of compound 7, details of energy-transfer experiments, and summary tables and summary figures for all experiments.

Acknowledgments: This work is funded by the NSF Award: 1453483.

Author Contributions: The manuscript was written using the contributions of all authors. Dana J. DiScenza and Nicole Serio designed the experiments; Dana J. DiScenza, Ella Culton, Molly Verderame and Julie Lynch performed the experiments; Dana J. DiScenza and Mindy Levine analyzed the data; and Dana J. DiScenza and Mindy Levine wrote the paper. All authors have given approval to the final version of the manuscript.

Conflicts of Interest: The authors declare no conflict of interest.

\section{References}

1. Peng, L.; Liu, S.; Feng, A.; Yuan, J. Polymeric nanocarriers based on cyclodextrins for drug delivery: Host-guest interaction as stimuli responsive linker. Mol. Pharm. 2017, 14, 2475-2486. [CrossRef]

2. Erdogar, N.; Varan, G.; Bilensoy, E. Amphiphilic cyclodextrin derivatives for targeted drug delivery to tumors. Curr. Top. Med. Chem. 2017, 17, 1521-1528. [CrossRef]

3. Loftsson, T.; Stefansson, E. Cyclodextrins and topical drug delivery to the anterior and posterior segments of the eye. Int. J. Pharm. 2017, 531, 413-423. [CrossRef]

4. Cagliero, C.; Sgorbini, B.; Cordero, C.; Liberto, E.; Rubiolo, P.; Bicchi, C. Enantioselective gas chromatography with derivatized cyclodextrins in the flavour and fragrance field. Israel J. Chem. 2016, 56, 925-939. [CrossRef]

5. Hapiot, F.; Menuel, S.; Ferreira, M.; Leger, B.; Bricout, H.; Tilloy, S.; Monflier, E. Catalysis in cyclodextrin-based unconventional reaction media: Recent developments and future opportunities. ACS Sustain. Chem. Eng. 2017, 5, 3598-3606. [CrossRef]

6. Chaudhuri, S.; Zaki, H.; Levine, M. Environmentally friendly procedure for the aqueous oxidation of benzyl alcohols to aldehydes with dibromodimethylhydantoin (DBDMH) and cyclodextrin: Scope and mechanistic insights. Synth. Commun. 2016, 46, 636-644. [CrossRef]

7. Chaudhuri, S.; Phelan, T.; Levine, M. Cyclodextrin-promoted Diels Alder reactions of a polycyclic aromatic hydrocarbon under mild reaction conditions. Tetrahedron Lett. 2015, 56, 1619-1623. [CrossRef]

8. Xin, X.; Wang, J.; Gong, C.; Xu, H.; Wang, R.; Ji, S.; Dong, H.; Meng, Q.; Zhang, L.; Dai, F.; et al. Cyclodextrin-based metal-organic nanotube as fluorescent probe for selective turn-on detection of hydrogen sulfide in living cells based on H2S-involved coordination mechanism. Sci. Rep. 2016, 6, 21951-21960. [CrossRef]

9. Teka, S.; Gaied, A.; Jaballah, N.; Xiaonan, S.; Majdoub, M. Thin sensing layer based on semi-conducting $\beta$-cyclodextrin rotaxane for toxic metals detection. Mater. Res. Bull. 2016, 74, 248-257. [CrossRef]

10. Bhopate, S.B.; Dhole, S.N. Inclusion complexation by cyclodextrin: A novel approach to improve solubility and bioavailability of poorly water soluble drug. Int. J. Pharm. 2014, 4, 175-188.

11. Dardeer, H.M. Importance of cyclodextrins into inclusion complexes. Int. J. Adv. Res. 2014, 2, 414-428. 
12. Park, S. Cyclic glucans enhance solubility of bioavailable flavonoids. Molecules 2016, 21, 556. [CrossRef] [PubMed]

13. Zoghbi, A.; Wang, B. Carvedilol solubility enhancement by inclusion complexation and solid dispersion: Review. J. Drug Deliv. Ther. 2015, 5, 1-8. [CrossRef]

14. Serio, N.; Moyano, D.F.; Rotello, V.M.; Levine, M. Array-based detection of persistent organic pollutants via cyclodextrin promoted energy transfer. Chem. Commun. 2015, 51, 11615-11618. [CrossRef] [PubMed]

15. Clapp, A.R.; Medintz, I.L.; Mattoussi, H. Forster resonance energy transfer investigations using quantum-dot fluorophores. ChemPhysChem 2006, 7, 47-57. [CrossRef] [PubMed]

16. DiScenza, D.J.; Verderame, M.; Levine, M. Detection of benzene and alkylated benzene derivatives in fuel contaminated environments. Clean Soil Air Water 2016, 44, 1621-1627. [CrossRef]

17. DiScenza, D.J.; Levine, M. Selective detection of non-aromatic pesticides via cyclodextrin-promoted fluorescence modulation. New J. Chem. 2016, 40, 789-793. [CrossRef]

18. Mako, T.; Marks, P.; Cook, N.; Levine, M. Fluorescent detection of polycyclic aromatic hydrocarbons in ternary cyclodextrin complexes. Supramol. Chem. 2012, 24, 743-747. [CrossRef]

19. Serio, N.; Prignano, L.; Peters, S.; Levine, M. Detection of medium-sized polycyclic aromatic hydrocarbons via fluorescence energy transfer. Polycycl. Aromat. Compound. 2014, 34, 561-572. [CrossRef] [PubMed]

20. Serio, N.; Miller, K.; Levine, M. Efficient detection of polycyclic aromatic hydrocarbons and polychlorinated biphenyls via three-component energy transfer. Chem. Commun. 2013, 49, 4821-4823. [CrossRef] [PubMed]

21. Serio, N.; Roque, J.; Badwal, A.; Levine, M. Rapid and efficient pesticide detection via cyclodextrin-promoted energy transfer. Analyst 2015, 140, 7503-7507. [CrossRef] [PubMed]

22. DiScenza, D.J.; Levine, M. Sensitive and selective detection of alcohols via fluorescence modulation. Supramol. Chem. 2016, 28, 881-891. [CrossRef]

23. Serio, N.; Chanthalyma, C.; Prignano, L.; Levine, M. Cyclodextrin-promoted energy transfer for broadly applicable small-molecule detection. Supramol. Chem. 2014, 26, 714-721. [CrossRef] [PubMed]

24. DiScenza, D.J.; Gareau, L.; Serio, N.; Roque, J.; Prignano, L.; Verderame, M.; Levine, M. Cyclodextrin-promoted detection of aromatic toxicants and toxicant metabolites in urine. Anal. Chem. Lett. 2016, 6, 345-353. [CrossRef]

25. DiScenza, D.J.; Lynch, J.; Verderame, M.; Serio, N.; Prignano, L.; Gareau, L.; Levine, M. Efficient fluorescence detection of aromatic toxicants and toxicant metabolites in human breast milk. Supramol. Chem. 2017, 1-11. [CrossRef]

26. Panja, S.; Chowdhury, P.; Chakravorti, S. Modulation of complexation of 4(1H-pyrrole-1-yl)-benzoic acid with $\beta$-cyclodextrin in aqueous and non-aqueous environments. Chem. Phys. Lett. 2004, 393, 409-415. [CrossRef]

27. Thomas, S.W., III; Joly, G.D.; Swager, T.M. Chemical sensors based on amplifying fluorescent conjugated polymers. Chem. Rev. 2007, 107, 1339-1386. [CrossRef] [PubMed]

28. Wagner, B.D. The use of coumarins as environmentally-sensitive fluorescent probes of heterogeneous inclusion systems. Molecules 2009, 14, 210-237. [CrossRef] [PubMed]

29. Perevoshchikova, I.V.; Kotova, E.A.; Antonenko, Y.N. Fluorescence correlation spectroscopy in biology, chemistry, and medicine. Biochemistry 2011, 76, 497-516. [CrossRef] [PubMed]

30. Pace, T.C.S.; Bohne, C. Dynamics of guest binding to supramolecular systems: Techniques and selected examples. Adv. Phys. Org. Chem. 2008, 42, 167-223. [CrossRef]

31. Wagner, B.D. Recent applications of host-guest inclusion in fluorescence-based trace analysis. Curr. Anal. Chem. 2007, 3, 183-195. [CrossRef]

32. Hamai, S. Complex formation of tetrakis(4-sulfonatophenyl)porphyrin with $\gamma$-cyclodextrin, phenylalanine, and tryptophan in aqueous solution. J. Incl. Phenom. Macrocycl. Chem. 2010, 67, 471-481. [CrossRef]

33. Hamai, S. Ternary inclusion complexes of $\gamma$-cyclodextrin with sodium 1-pyrenesulfonate and cationic and anionic organic compounds having an alkyl chain in aqueous solution. J. Incl. Phenom. Macrocycl. Chem. 2009, 63, 77-86. [CrossRef]

34. Rakkaew, P.; Suksiriworapong, J.; Chantasart, D. $\beta$-Cyclodextrin-based ternary complexes of haloperidol and organic acids: The effect of organic acids on the drug solubility enhancement. Pharm. Dev. Technol. 2017, 1-8. [CrossRef] [PubMed] 
35. Shepherd, J.L.; Kell, A.; Chung, E.; Sinclar, C.W.; Workentin, M.S.; Bizzotto, D. Selective reductive desorption of a SAM-coated gold electrode revealed using fluorescence microscopy. J. Am. Chem. Soc. 2004, 126, 8329-8335. [CrossRef] [PubMed]

36. Kodama, S.; Yamamoto, A.; Matsunaga, A.; Toriba, A.; Hayakawa, K. Micellar electrokinetic chromatography of monohydroxybenzo[a]pyrene positional isomers using $\gamma$-cyclodextrin. Analyst 2000, 125, 1555-1559. [CrossRef]

37. Carrillo, I.; Quintana, C.; Esteva, A.M.; Hernandez, L.; Hernandez, P. Self-assembled submonolayer of $\beta$-cyclodextrins on gold electrode for the selective determination of 4-aminobiphenyl. Electroanalysis 2011, 23, 2862-2869. [CrossRef]

38. Dyck, A.S.M.; Kisiel, U.; Bohne, C. Dynamics for the assembly of pyrene- $\gamma$-cyclodextrin host-guest complexes. J. Phys. Chem. B 2003, 107, 11652-11659. [CrossRef]

39. Hamdi, H.; Abderrahim, R.; Meganem, F. Spectroscopic studies of inclusion complex of $\beta$-cyclodextrin and benzidine diammonium dipicrate. Spectrochim. Acta Part A 2010, 75, 32-36. [CrossRef] [PubMed]

40. Krishnan, S.B.; Gopidas, K.R. Observation of supramolecular chirality in a hierarchically self-assembled mixed-stack charge-transfer complex. Chem. Eur. J. 2017, 23, 9600-9606. [CrossRef] [PubMed]

41. Diaz-Salmeron, R.; Chaab, I.; Carn, F.; Djabourov, M.; Bouchemal, K. Pickering emulsions with $\alpha$-cyclodextrin inclusions: Structure and thermal stability. J. Colloid Interface Sci. 2016, 482, 48-57. [CrossRef] [PubMed]

42. Lemli, B.; Peles, J.; Kollar, L.; Nagy, G.; Kunsagi-Mate, S. The rate of host-guest complex formation of some calixarene derivatives towards neutral aromatic guests. Supramol. Chem. 2006, 18, 251-256. [CrossRef]

43. Cervero, M.; Mendicuti, F. Inclusion complexes of dimethyl 2,6-naphthalenedicarboxylate with $\alpha$ - and $\beta$-cyclodextrins in aqueous medium: Thermodynamics and molecular mechanics studies. J. Phys. Chem. $B$ 2000, 104, 1572-1580. [CrossRef]

44. Hiroshiba, N.; Morimoto, K.; Hayakawa, R.; Chikyow, T.; Wakayama, Y.; Matsuishi, K. Study of the exciton relaxation and recombination processes of a heteromolecular interface fabricated by a molecular superlattice growth technique. Chem. Phys. Lett. 2011, 512, 227-230. [CrossRef]

45. Macanita, A.L.; Zachariasse, K.A. Viscosity dependence of intramolecular excimer formation with 1,5-Bis(1-pyrenylcarboxy)pentane in alkane solvents as a function of temperature. J. Phys. Chem. A 2011, 115, 3183-3195. [CrossRef] [PubMed]

46. Banerjee, S.; Baiardi, A.; Bloino, J.; Barone, V. Vibronic effects on rates of excitation energy transfer and their temperature dependence. J. Chem. Theory Comput. 2016, 12, 2357-2365. [CrossRef] [PubMed]

47. Eersels, K.; Lieberzeit, P.; Wagner, P. A review on synthetic receptors for bioparticle detection created by surface-imprinting techniques-from principles to applications. ACS Sens. 2016, 1, 1171-1187. [CrossRef]

48. Aki, H.; Niiya, T.; Iwase, Y.; Yamamoto, M. Multimodal inclusion complexes between barbiturates and 2-hydroxypropyl- $\beta$-cyclodextrin in aqueous solution: Isothermal titration microcalorimetry, $13 \mathrm{C}$ NMR spectrometry, and molecular dynamics simulation. J. Pharm. Sci. 2001, 90, 1186-1197. [CrossRef] [PubMed]

49. Strokopytov, B.; Penninga, D.; Rozeboom, H.J.; Kalk, K.H.; Dijkhuizen, L.; Dijkstra, B.W. X-ray structure of cyclodextrin glycosyltransferase complexed with acarbose. implications for the catalytic mechanism of glycosidases. Biochemistry 1995, 34, 2234-2240. [CrossRef] [PubMed]

50. Kotake, Y.; Janzen, E.G. Effect of $\mathrm{pH}$ and salt concentration on bimodal inclusion of a nitroxide by cyclodextrins. J. Am. Chem. Soc. 1989, 111, 7319-7323. [CrossRef]

51. Rossi, B.; Venuti, V.; D’Amico, F.; Gessini, A.; Mele, A.; Punta, C.; Melone, L.; Crupi, V.; Majolino, D.; Masciovecchio, C. Guest-matrix interactions affect the solvation of cyclodextrin-based polymeric hydrogels: A UV Raman scattering study. Soft Matter 2016, 12, 8861-8868. [CrossRef] [PubMed]

52. Junquera, E.; Ruiz, D.; Aicart, E. Role of hydrophobic effect on the noncovalent interactions between salicylic acid and a series of $\beta$-cyclodextrins. J. Colloid Interface Sci. 1999, 216, 154-160. [CrossRef] [PubMed]

53. Tagiuri, A.; Mohamedali, M.; Henni, A. Dissociation constant (pKa) and thermodynamic properties of some tertiary and cyclic amines from (298 to 333) K. J. Chem. Eng. Data 2016, 61, 247-254. [CrossRef]

54. Costero, A.M.; Gavina, P.; Rodriguez-Muniz, G.M.; Gil, S. N-biphenyl thioureas as carboxylate receptors. Effect of the ligand substituents on the geometry of the complexes. Tetrahedron 2006, 62, 8571-8577. [CrossRef]

55. Loftsson, T.; Brewster, M.E. Cyclodextrins as functional excipients: Methods to enhance complexation efficiency. J. Pharm. Sci. 2012, 101, 3019-3032. [CrossRef] [PubMed] 
56. Hameed, M.A.; Nazim, S.; Khan, T. A recent trends in enhancement of solubility and dissolution rate of poorly soluble hydrophobic drugs by using physical and chemical modifications. J. Drug Discov. Ther. 2013, 1, 13-24.

57. Parve, B.; Shinde, P.; Rawat, S.; Rathod, S.; Waghmode, G. Solubility enhancement techniques: A review. World J. Pharm. Pharm. Sci. 2014, 3, 400-422.

58. Curtis, R.A.; Prausnitz, J.M.; Blanch, H.W. Protein-protein and protein-salt interactions in aqueous protein solutions containing concentrated electrolytes. Biotechnol. Bioeng. 1998, 57, 11-21. [CrossRef]

59. Parui, S.; Manna, R.N.; Jana, B. Destabilization of hydrophobic core of chicken villin headpiece in guanidinium chloride induced denaturation: hint of $\pi$-cation interaction. J. Phys. Chem. B 2016, 120, 9599-9607. [CrossRef] [PubMed]

60. Huan, J.; Catena, G.C.; Bright, F.V. Fluorescence-based investigations of alcohol co-solvents on the nature of cyclodextrin inclusion complexation. Appl. Spectrosc. 1992, 46, 606-614. [CrossRef]

61. Zhang, H.; Ge, C.; van der Spoel, D.; Feng, W.; Tan, T. Insight into the structural deformations of $\beta$-cyclodextrin caused by alcohol cosolvents and guest molecules. J. Phys. Chem. B 2012, 116, 3880-3889. [CrossRef] [PubMed]

62. Shin, H.D.; Kim, J.H.; Kim, T.K.; Kim, S.H.; Lee, Y.H. Esterification of hydrophobic substrates by lipase in the cyclodextrin induced emulsion reaction system. Enzyme Microb. Technol. 2002, 30, 835-842. [CrossRef]

63. Donze, C.; Coleman, A.W. Solvent effects in competition between guest molecules for $\beta$-cyclodextrin. J. Incl. Phenom. Mol. Recognit. Chem. 1995, 23, 11-21. [CrossRef]

64. Patonay, G.; Fowler, K.; Shapira, A.; Nelson, G.; Warner, I.M. Cyclodextrin complexes of polyaromatic hydrocarbons in the presence of aliphatic alcohols. J Incl. Phenom. 1987, 5, 717-723. [CrossRef]

(C) 2017 by the authors. Licensee MDPI, Basel, Switzerland. This article is an open access article distributed under the terms and conditions of the Creative Commons Attribution (CC BY) license (http:/ / creativecommons.org/licenses/by/4.0/). 